\title{
Genetic and environmental factors of schizophrenia and autism spectrum disorder: insights from twin studies
}

\author{
Akira Imamura $^{1}$ (D) Yoshiro Morimoto ${ }^{2,3} \cdot$ Shinji Ono $^{3} \cdot$ Naohiro Kurotaki $^{4} \cdot$ Shinji Kanegae $^{1} \cdot$ Naoki Yamamoto $^{1,2}$. \\ Hirohisa Kinoshita ${ }^{2} \cdot$ Takahiro Tsujita $^{5} \cdot$ Yuji Okazaki $^{6,7} \cdot$ Hiroki Ozawa $^{1,2}$
}

Received: 30 January 2020 / Accepted: 5 April 2020 / Published online: 13 April 2020

(c) The Author(s) 2020

\begin{abstract}
Twin studies of psychiatric disorders such as schizophrenia and autism spectrum disorder have employed epidemiological approaches that determine heritability by comparing the concordance rate between monozygotic twins (MZs) and dizygotic twins. The basis for these studies is that MZs share 100\% of their genetic information. Recently, biological studies based on molecular methods are now being increasingly applied to examine the differences between MZs discordance for psychiatric disorders to unravel their possible causes. Although recent advances in next-generation sequencing have increased the accuracy of this line of research, there has been greater emphasis placed on epigenetic changes versus DNA sequence changes as the probable cause of discordant psychiatric disorders in MZs. Since the epigenetic status differs in each tissue type, in addition to the DNA from the peripheral blood, studies using DNA from nerve cells induced from postmortem brains or induced pluripotent stem cells are being carried out. Although it was originally thought that epigenetic changes occurred as a result of environmental factors, and thus were not transmittable, it is now known that such changes might possibly be transmitted between generations. Therefore, the potential possible effects of intestinal flora inside the body are currently being investigated as a cause of discordance in MZs. As a result, twin studies of psychiatric disorders are greatly contributing to the elucidation of genetic and environmental factors in the etiology of psychiatric conditions.
\end{abstract}

Keywords Schizophrenia $\cdot$ Autism spectrum disorder · Twin study $\cdot$ Psychiatric disorders $\cdot$ Epigenetics

\section{Introduction}

Twins have long been a source of mystery. In Greco-Roman mythology, the twin-pair of one human and one immortal (Castor and Pollux; Gemini) served as an important example

Akira Imamura

aimamura@nagasaki-u.ac.jp

1 Child and Adolescent Psychiatry Community Partnership Unit, Nagasaki University Hospital, Nagasaki, Japan

2 Unit of Translation Medicine, Department of Neuropsychiatry, Nagasaki University Graduate School of Biomedical Sciences, Nagasaki, Japan

3 Department of Human Genetics, Atomic Bomb Disease Institute, Nagasaki University Graduate School of Biomedical Sciences, Nagasaki, Japan

4 Department of Clinical Psychiatry, Graduate School of Medicine, Kagawa University, Kita-gun, Japan

5 Goseikai Hironaka Hospital, Nagasaki, Japan

6 Koseikai Michinoo Hospital, Nagasaki, Japan

7 Tokyo Metropolitan Matsuzawa Hospital, Tokyo, Japan of "discordant" twins. At the end of the nineteenth century, Francis Golton was the first to consider twins as a useful scientific model, questioning whether human traits originated from genetic or environmental causes. This line of inquiry led to the "nature versus nurture" debate that is still argued to this day (Torrey et al. 1994a).

In epidemiological twin studies, comparisons of the concordance rate between monozygotic twins (MZs) and dizygotic twins (DZs) are very important. Since MZs are considered to share $100 \%$ of their genetic information, their concordance rate is higher compared to DZs who share about $50 \%$ of the genetic information. Thus, genetic factors are thought to play a major role as compared to environmental factors (Rutter 2006). In psychiatry, there is a much higher concordance rate for schizophrenia (SCZ) and autism 
spectrum disorder (ASD) in MZs versus DZs (Hilker et al. 2018; Sandin et al. 2017). As a result, researchers are beginning to think that genetic factors play a major role in the onset of these conditions.

The similarity of the genetic information in MZs provides a useful means for determining the disorder-causing role of environmental factors. In recent years, studies on the differences between genomic and epigenomic characteristics of MZs have led to the development of new approaches for elucidating the etiology of psychiatric disorders (Liang et al. 2019; Morimoto et al. 2017). The current paper focuses on epidemiological and molecular genetic research studies in MZs with the purpose of unravelling useful insights on factors that can lead to SCZ and ASD.

\section{Epidemiological twin studies}

\section{Studies on heritability}

\section{Heritability of SCZ}

In 1899, Emil Kraepelin classified psychosis into 'dementia praecox' [Schizophrenia in DSM-5 (American Psychiatric Association 2013)] and 'manisch-depressiven Irreseins' (Bipolar Disorder in DSM-5). This has had a significant impact on subsequent diagnostic classifications. At that time, the idea of urbanization and mental stress as factors that could cause psychosis in young people was widely accepted. However, Kraepelin argued for the involvement of a biological component (Kendler and Engstrom 2018). Eugen Bleuler agreed with Kraepelin's theory but considered hallucinations and delusions to be secondary with conditions resulting from some disruption in the cognitive processing regarded as psychopathologies (Maatz and Hoff 2014).

In the 1940s, the idea that SCZ was due to mother-child relationships was widely accepted with Fromm-Reichman's term, "schizophrenogenic mother", emphasizing the role that the environment played in the onset of SCZ (Fromm-Reichman 1948). However, epidemiological studies such as adoption studies, twin studies, and high-risk studies support the idea that genetic factors play a significant role with regard to the cause of SCZ (Henriksen et al. 2017).

In SCZ twin studies, MZs have been reported to exhibit a much higher concordance rate compared to DZs. Researchers have used two statistical methods to examine the twin concordance rate: the probandwise method and the pairwise method. The pairwise method is able to detect twin pairs with one or two affected twins while the probandwise method evaluates each twin as a distinct target. When using the latter method, if both twins are detected with the condition, it is possible that the same twin may be counted twice. Hence, this approach produces a higher concordance rate as compared to the pairwise method (Torrey et al. 1994b). Currently, the probandwise method is more commonly used by researchers. Using the probandwise method, Farmer et al. (1987) reported SCZ concordance rates in the DSM, Third Edition (DSM-III) were $47.6 \%$ and $9.5 \%$ for MZs and DZs, respectively. Onstad et al. (1991) examined the MZ and DZ concordance rate and reported them to be $48.0 \%$ and $4.0 \%$, respectively, for SCZ in the DSM-III Revised Edition (DSM-III-R).

In a large-scale survey of twins in Nagasaki Prefecture that was conducted to investigate the DSM-III-R SCZ concordance rate in Japan, Okazaki (1995) reported a concordance rate of $11 / 22(50.0 \%)$ when using the probandwise method, 7/18 (38.9\%) when using the pairwise method for MZs, and 1/7 (14.0\%) for both methods for DZs. During the same period, Torrey (1992) evaluated the results from eight studies and reported that the concordance rate among MZs with SCZ was 163/405 (40.2\%) and 97/341 (28.4\%) when using the probandwise and pairwise methods, respectively. For DZs, results were 62/427 (14.5\%) and 36/587 (6.1\%), respectively, when using the probandwise and pairwise methods.

A recent study by Hilker et al. (2018) used data from the Danish Twin Registry and Danish Psychiatric Registry to examine the concordance rate of $\mathrm{SCZ}$ and its spectrum (F2 code ICD-10) in more than 30,000 twin pairs. When using the probandwise method, they found the $\mathrm{SCZ}$ concordance rate for MZs and DZs was $33 \%$ and $7 \%$, respectively. The SCZ heritability rate was $79 \%$ while the heritability rate of the SCZ spectrum disorders was $73 \%$.

Since the SCZ twin concordance rate was much higher in MZs compared to DZs, this clearly shows that there is involvement of a genetic component in the disorder onset.

\section{Heritability of ASD}

Kanner (1943) examined eleven autism cases and suggested that they could potentially be congenital disorders. He also recorded the characteristic personalities of the parents, stating that they were intelligent, had a moderately high social status, while they were unsociable, emotionally fervent, compulsive, unwarm, and unemotional towards their children. In contrast, Asperger $(1938,1944)$ hypothesized there was a predisposition for autism to be passed on from parent to child, a theory implying multiple-factor inheritance. Thus, over a long period of time, Kanner's remark has led to the wrong assumption and the commonly accepted view that autism was the result of the mother-child relationship. Moreover, a large number of researchers believed that being raised in an environment similar to the cold parenting style described by Kanner predisposed children to autism. Bruno Bettelheim described this term as "refrigerator mother", 
with this notion then strongly adopted by the psychoanalysis field (Mandy and Lai 2016).

Starting in the 1970s, Rutter et al. argued that autism was, in fact, a congenital cognitive disorder caused by strong genetic factors, which marked the eventual end to theories suggesting psychological or environmental factors were primarily responsible for causing autism (Rutter and Bartak 1971). In addition, twin studies have also shown that autism is associated with biological factors, especially those of genetic origin. Folstein and Rutter (1997) analyzed 21 twin pairs and reported that the MZs concordance rate for autism was $36 \%$ (82\%, if broader phenotypes were included), while the DZs rate was $0 \%(10 \%$, if broader phenotypes were included) when using the pairwise method. The heritability rate was calculated to be $91-93 \%$ in this group. Subsequent works by Rutter et al. demonstrated that autism was a disorder with a particularly high heritability rate. Later, the concept of "autism spectrum disorder (ASD)" was developed to broaden the diagnosis and which included the "Kanner type" and "Asperger type" (Wing 1996).

In 2011, Hallmayer et al. calculated the heritability rate for 192 pairs of twins and reported a heritability rate of $37 \%$ (95\% CI 8-84\%) for autism and 38\% (95\% CI 14-67\%) for ASD. The heritability of autism and ASD with shared environmental factors was 55\% (95\% CI 9-814\%) and 58\% (95\% CI 30-80\%), respectively. Since the heritability rate of autism was shown to be much lower than expected, this led the researchers to reconsider the notion of the heritability of autism.

In 2017, Sandin et al. conducted a study of 37,570 twin pairs, 2,642,064 full sibling pairs, 432,281 maternal halfsibling pairs, and 445,531 paternal half-sibling pairs. They found that the heritability rate for ASD was $83 \%$ (95\% CI 79-87\%) and the ASD heritability rate from twin studies alone was $87 \%$ (95\% CI 68-96\%). These results demonstrated the greater influence of genetic factors compared to environmental factors.

Currently, a large percentage of researchers consider that ASD is one of the highest heritability rate common disorders.

\section{Challenges in heritability research}

Several heritability studies have been carried out for different disorders. Figure 1 shows the concordance rate for
Fig. 1 Concordance rate of MZs and DZs for various disorders. Originally cited and published in the study of Schumacher and Petronis (2006). We have added data on ADHD (Pingault et al. 2015) to the original graph that is pictured here

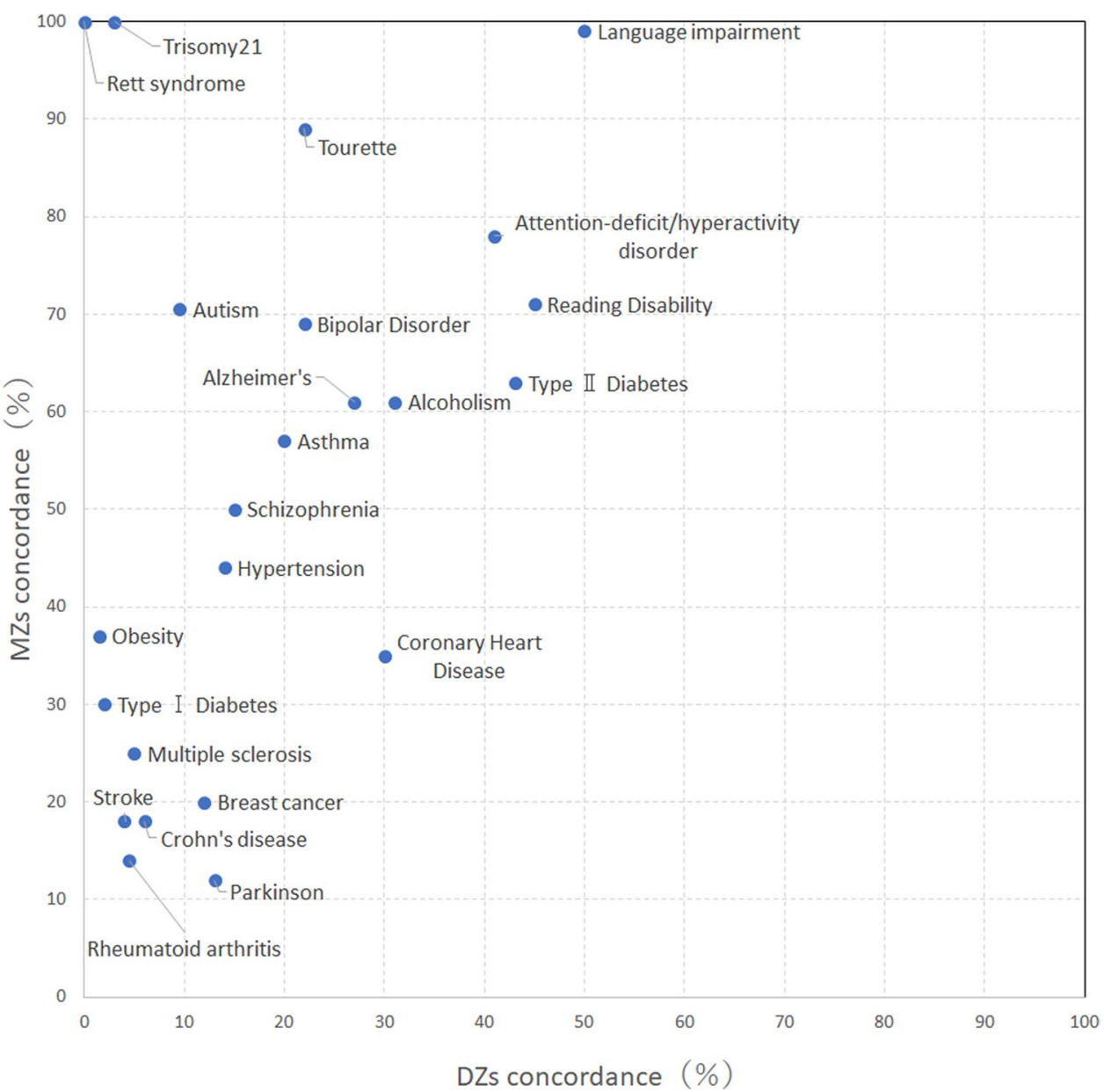


MZs and DZs in these various disorders. Results suggested that the concordance rate for MZs in ASD and SCZ is much higher than the concordance rate for DZs.

Generally, the heritability rate is calculated from the correlation coefficient "rMZ" for MZs and "rDZ" for DZs. It is represented by the following equation:

$\mathrm{h} 2=2(\mathrm{rMZ}-\mathrm{rDZ})$,

where $\mathrm{h} 2=$ heritability rate, $\mathrm{rMZ}=\mathrm{MZ}$ concordance rate and $\mathrm{rDZ}=\mathrm{DZ}$ concordance rate.

Figure 2 shows the relationship between the heritability and shared environmental factor.

However, the problem when using this method is that the diagnostic concordance rate varies depending on how the affected and non-affected twins are determined. For instance, the designation for autism advocated by Kanner was significantly different from the current ASD diagnostic criteria. Moreover, it has been reported that when using the broader autistic phenotype principle, this makes the concordance rate more variable (Le Couteur et al. 1996).

Furthermore, not only the heritability rate but both the "shared environmental factors" (rMZ-h2) and "nonshared environmental factors" (1-rMZ) need to be considered (Hallmayer et al. 2011). Although the intrauterine environment has previously been considered to be a shared environment, it has now been reported that studies of MZs cannot confirm that the intrauterine state is the same. An example of this is the twin transfusion syndrome (Djaafri et al. 2017). Moreover, if the epigenetic mutations or somatic mosaic mutations are acquired by one twin, the twins will then become "discordant." Such factors are considered to be a part of the non-shared environment and disregarding these will only create different forms of misunderstanding. Recently, epigenetic changes experienced

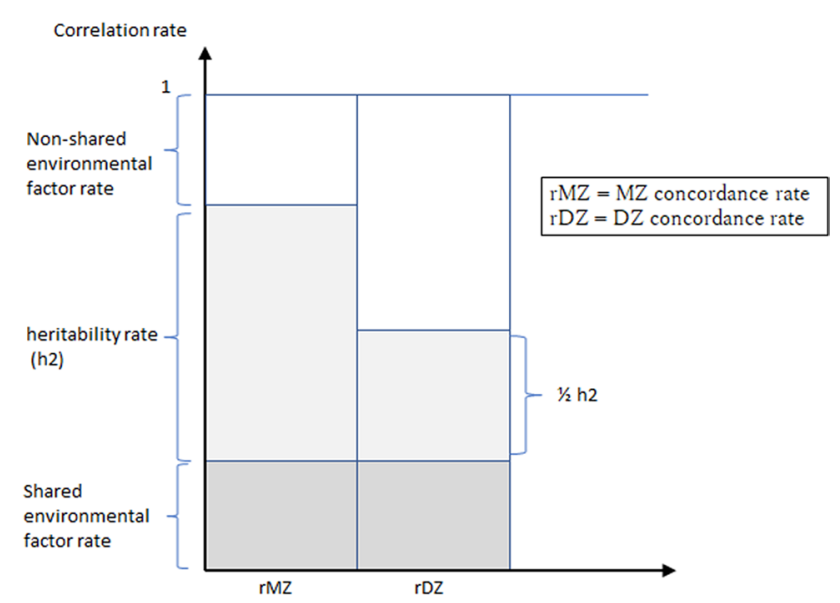

Fig. 2 Heritability and shared environmental factor. This figure cites and was created based on the study by Hrubec and Neel (1981) by parents due to environmental factors have been reported to be "transgenerational epigenetic inheritance" such as germ line-inherited H3K27me3 (Zenk et al. 2017), which makes it difficult to separate genetic and environmental factors (Nagy and Turecki 2015).

\section{Genetic overlap}

Genetic overlaps have been recently observed between various mental disorders. In the 2010s, researchers examined the genetic background and overlap for SCZ, ASD, attentiondeficit/ hyperactivity disorder (ADHD), bipolar disorder, depression, and other mental disorders (Cross-Disorder Group of the Psychiatric Genomics Consortium 2013; Zhao and Nyholt 2017; Gandal et al. 2018).

Epidemiological twin studies have also reported finding such genetic overlaps. Taylor et al. (2015) studied the genetic overlap between the ASD trait (autism spectrum condition (ASC)) and the SCZ trait (psychotic experiences). In their study of approximately 5000 twin pairs in the UK, ASC was weakly correlated with psychotic experiences (paranoia and hallucinations) and modestly correlated with cognitive disorganization in adolescence.

Another twin study attempted to investigate the genetic overlap between SCZ and bipolar disorder (Johansson et al. 2019) while another twin study showed a strong correlation between ASD symptoms (especially restrictive repetitive behaviors) and ADHD symptoms (inattention and hyperactivity-impulsivity) (Polderman et al. 2014). These studies suggest the existence of a genetic overlap in MZs with psychiatric disorders.

\section{MZ studies of molecular genetics}

\section{Genomic differences}

Originally, discordant MZs have been used to investigate the effect of environmental factors from the point of view that if MZs with the same genetic information exhibited different phenotypes, it might be due to various environmental factors. Since the 1980s, chromosomal abnormalities that resulted in different phenotypes have only been reported to occur in one individual from an MZ pair [Ring chromosome 18 syndrome (Hata et al. 1982)]. In other similar cases, MZs with phenotype differences due to genomic discrepancies, such as the genomic printing mechanism collapse [Beckwith-Wiedemann syndrome (Weksberg et al. 2002) and others], repeat sequences expansion [Fragile $\times$ syndrome (Kruyer et al. 1994) and others] have also been observed.

In 1990s, the earliest MZs genetic studies applied the restriction enzyme method in which DNA fragments were treated with restriction enzymes and then run on an 
electrophoresis gel for analysis. The use of DNA microarray technology allowed scholars to determine differences in the genomes of the discordant MZs. Kakiuchi et al. (2003) of RIKEN Brain Science Institute, Japan collaborated with our lab to conduct DNA microarray (Affymetrix Hu95A Chip, including over 12,600 probes) on two pairs of discordant bipolar cases. They found that a single nucleotide polymorphism (SNP) on the XBP1 gene. XBP1 is involved in the endoplasmic reticulum stress response, and genopolymorphic XBP1 has been shown to increase the risk of bipolar disorder. Kakiuchi et al. (2008) also conducted microarray experiments in two cases of MZs with SCZ (Affymetrix HU133A, 22,000 probes) and found SNP mutations in the adrenomedullin and sepx 1 genes, which might be biomarkers of SCZ.

Since the late 2000s, studies on the copy number variation $(\mathrm{CNV})$ in mental disorders have been ongoing, particularly for SCZ and ASD. Therefore, twin studies have been used to investigate CNV. In 2010, Ono et al. conducted microarray experiments on three MZ SCZ polymorphisms (AffymeTrix Genome-Wide Human SNP Array 6.0; 906,600 or more SNP probes, including 946,000 copy count probes). They examined SNPs and CNVs between twins. The SNP analysis showed 36 loci with the potential loss of heterozygosity in affected twins while the copy number analysis revealed 120 loci with potential CNV differences. Ono et al. (2010) further conducted direct DNA sequencing and quantitative PCR and found no genomic alternations between twins. They concluded that the phenotype mismatch among MZs most likely involved epigenetic changes as a result of environmental events.

In 2017, Morimoto et al. conducted whole-exome sequencing on three $\mathrm{MZ}$ cases involving familial SCZ, one $\mathrm{MZ}$ case with ASD, and one MZ case with a gender identity disorder. A next-generation sequencer was used to produce deep sequencing and revealed three affected alleles between the twins with the gender identity disorder. It was hypothesized that these alleles were the result of somatic cell mosaicism that occurred during development, which indicated that mosaicism is an important mechanism in the generation of MZ differences.

Although the development of deep sequencing technology has enabled such new discoveries, the majority of differences between MZs are believed to be due to epigenetic mutations, as it is rare for somatic cell mutations to cause phenotype differences.

\section{Epigenomic differences}

The term epigenetics refers to postnatal modifications of gene expression without changes of DNA sequences. DNA methylation, chemical modification of histone proteins, non-coding RNA, and other mechanisms are involved in epigenetic regulation. Epigenetic factors are believed to play a vital role in human twin variation, in addition to causing a variety of diseases such as cancer, when abnormally regulated (Tabatabaiefar et al. 2019).

Another concept related to epigenetics is the concept of the Developmental Origins of Health and Disease (DOHaD). $\mathrm{DOHaD}$ considers various environmental factors from the fetal period to the developmental period that subsequently affect health in adulthood and other post-developmental factors that influence the onset of a disease by an epigenetic mechanism. Mental disorders are also believed to be caused by the same mechanism (O'Donnell and Meaney 2017).

In one of the earliest epigenetic studies of psychiatric disorders, Tsujita et al. (1998) used the restriction landmark genome scanning method to investigate the genomes of MZs, one with SCZ and the other without any health issues. The authors identified two spots out of nearly 2000 spots that were potential indicators of biological differences between the twin-pairs. Since they used the methylation-sensitive Not 1 enzyme, they speculated some postzygotic events could lead to epigenetic DNA modification in one twin that may also account for the observed phenotypic variation.

Later, many researchers started using "bisulfite" to differentiate cytosine and methylated cytosine in studies that examine DNA methylation (Kinoshita et al. 2013; Liang et al. 2019). With bisulfite, cytosine is deaminated and converted to uracil, while methylated cytosine is left in its original state. In many studies, the use of bisulfite made it possible to compare the state of DNA methylation between twins. Recent research has focused on the use of microarrays in genome-wide studies, which are referred to as an epigenome-wide association study.

In a study on epigenetic changes in SCZ discordant MZs, Castellani et al. (2015a, b) used a NimbleGen Methylation Promoter Microarray to examine differences in the DNA methylation between epigenomes of twins. Their results found three sets of gene clusters in the DNA methylation and two common networks that were potentially responsible for the onset of SCZ. These types of experiments are considered to be useful when studying SCZ etiology.

Table 1 shows the history of genetic and epigenetic discordant MZ studies for SCZ and ASD. The results of the technological progress in these research fields that are in many of the studies suggest that discordant MZs sometimes exhibit discordant genetic or epigenetic features. However, these findings were not definitively confirmed.

Future research into the epigenetic differences between twins is expected to heavily focus on histone chemical modifications and microRNA activity (Sarachana et al. 2010). 


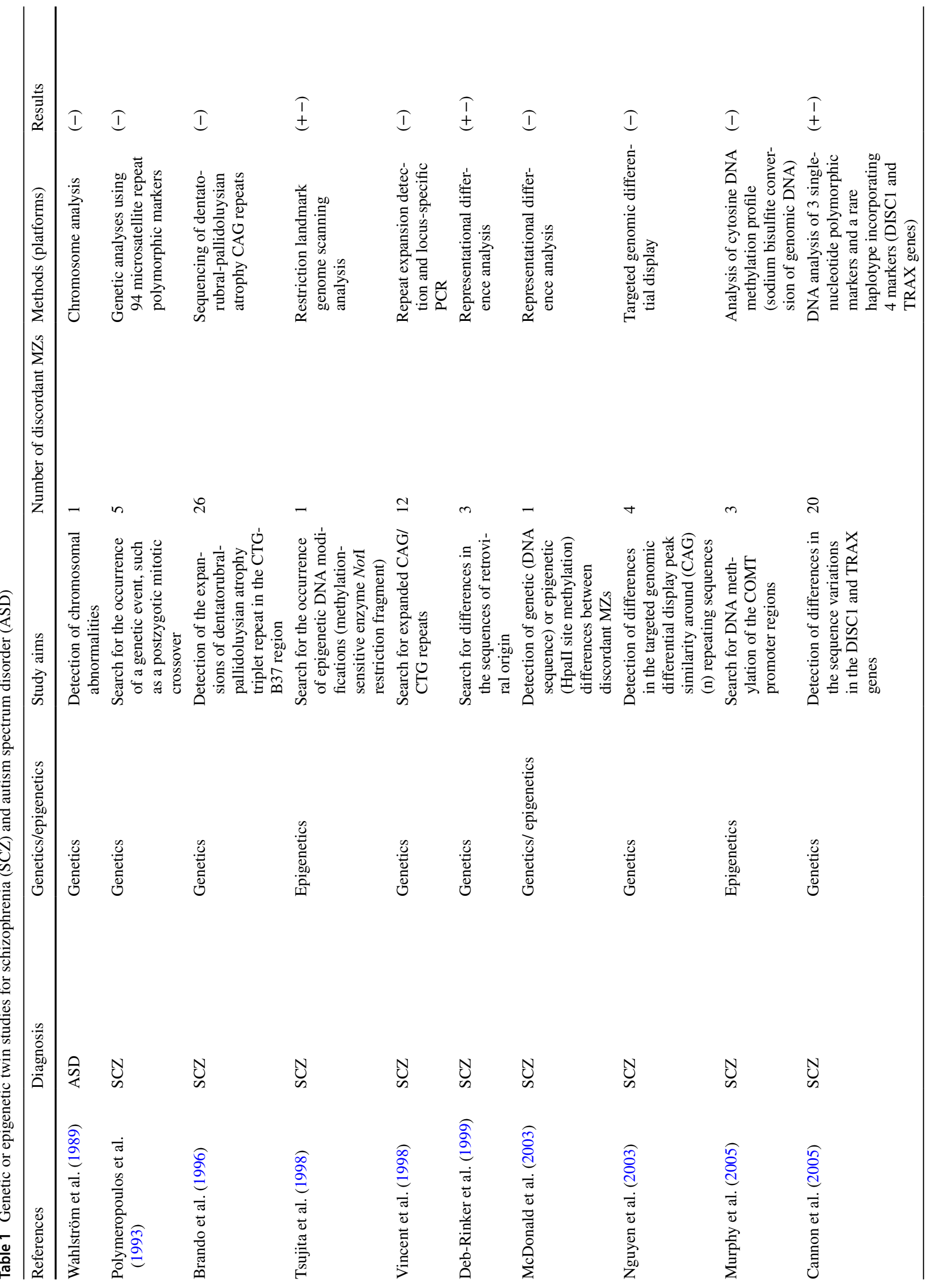




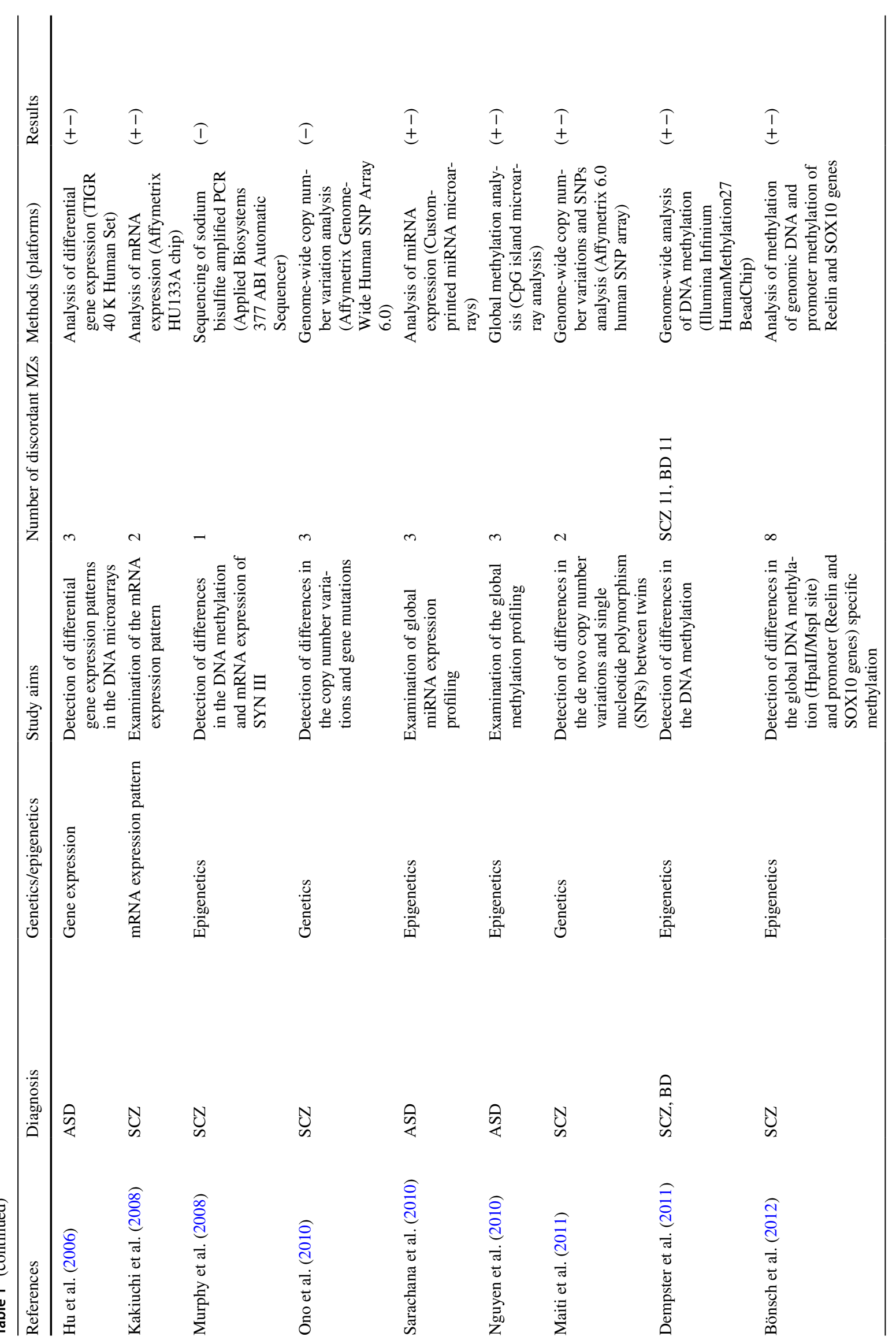




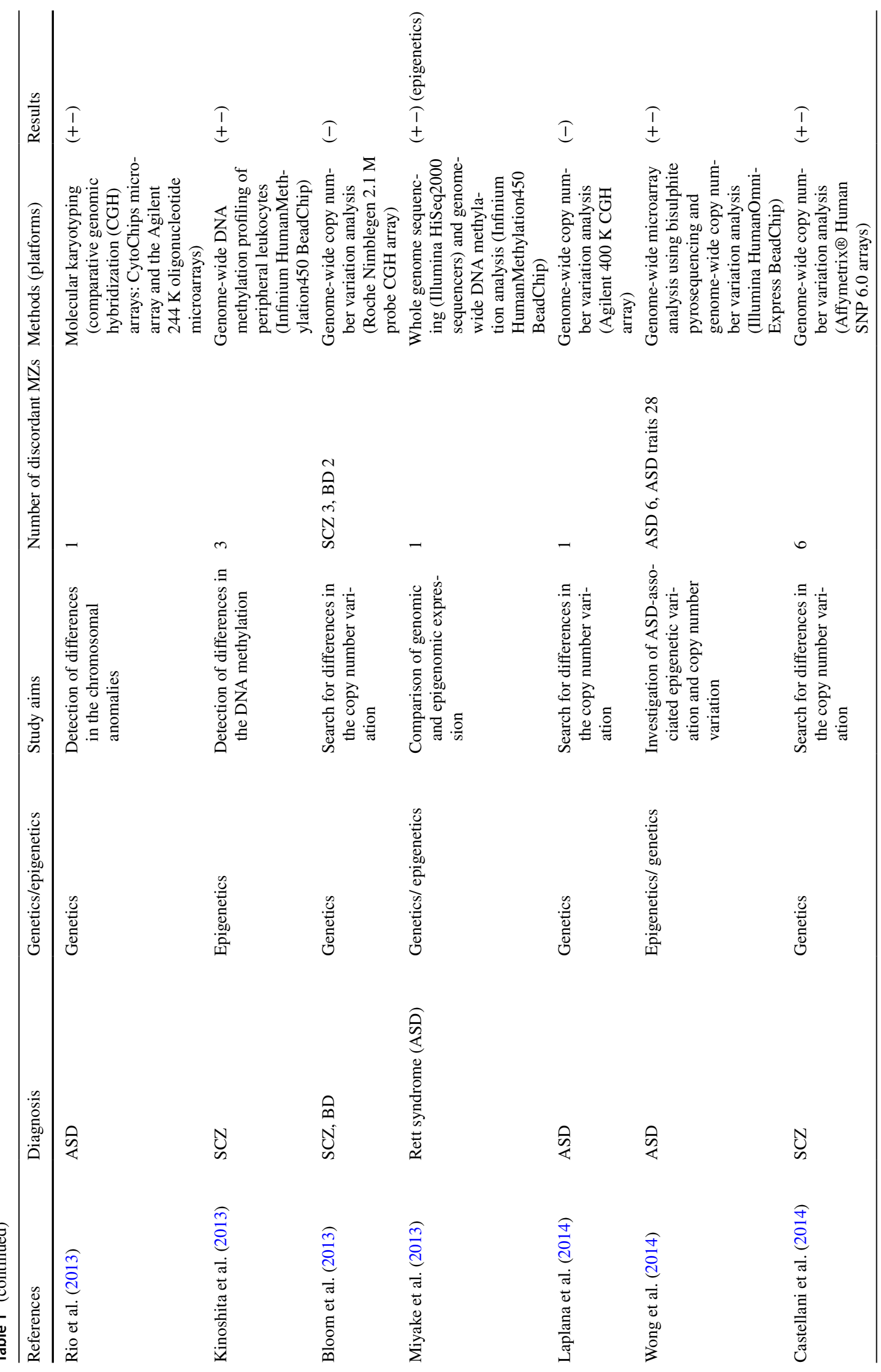




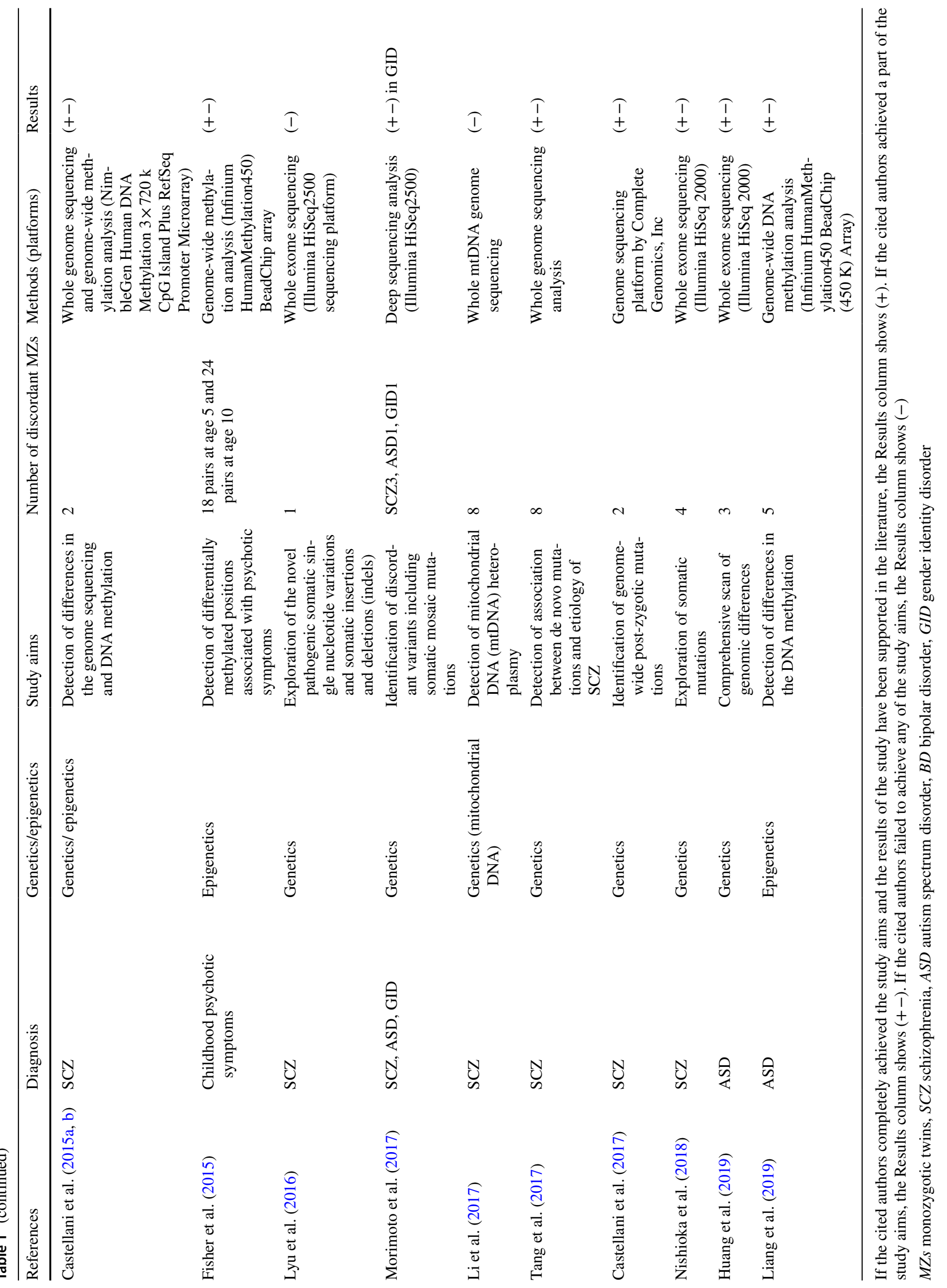




\section{Recent issues}

In twin studies of SCZ and ASD, attempts have been made to identify the cause of onset from differences in neuroimaging research of MZs. MRI studies showed that twins with SCZ had a smaller hippocampus, thalamus, prefrontal cortex and various other areas as compared to the healthy co-twins (Besteher et al. 2020). Other researchers examining twins reported smaller white matter volumes were related to SCZ (Picchioni et al. 2017; Hulshoff Pol et al. 2012). Recently, diffusion tensor imaging studies have revealed impairment of the white matter that was related to the deficits of the oligodendrocyte and cognitive dysfunction in SCZ patients (Camchong et al. 2009). Furthermore, other molecular studies have shown that oligodendrocyte-related genes were differentially expressed in patients with SCZ (Åberg et al. 2006; Haroutunian et al. 2007; Kerns et al. 2010; Raabe et al. 2019). As described above in the recent twin research, the number of studies integrating not only neuroimaging but also brain functions and molecular genetic findings have been increasing.

With regard to the results of environmental factors in twin studies, various perinatal factors, such as low birth weight, hypoxia, and jaundice, are thought to affect the development of SCZ and ASD (Torrey et al. 1994c; Froehlich-Santino et al. 2014). Perinatal hypoxia is especially considered to be one of the most important factors, as it can cause brain damage related to myelin dysfunction that is the result of oligodendrocyte impairment or inflammation involving microglia (van Tilborg et al. 2018; Picchioni et al. 2017). Other recent studies using genetic or epigenetic methods have also been conducted to verify that prenatal hypoxia plays a role in the development of SCZ (Schmidt-Kastner et al. 2012; PalmaGudiel et al. 2019).

In recent years, studies on intestinal flora have been ongoing in connection with epigenetic investigations. Many of these studies have focused on the relationship between ASD and the intestinal flora (Mangiola et al. 2016; Ding et al. 2017). In MZs, the intestines are completely sterile before birth, but are soon colonized by a large number of bacteria following delivery. The difference in the intestinal environments between MZs depends on several factors, including breast-fed versus formula-fed, vaginal versus $\mathrm{C}$-section birth, maternal stress, developmental environment, and drugs taken by the mother. Although intestinal floras are clearly individual factors, they can be classified as environmental factors. These types of factors have not been previously taken into consideration. With future work on different intestinal environments between MZs, there is room for the development of a hypothesis built on epigenetic factors related to the immune system that is influenced by intestinal floras with regard to the etiology of ASD and SCZ.
One of the most difficult problems in epigenetic research for mental disorders is that the epigenome differs significantly depending on the tissue type. Since these types of experiments can only examine the DNA methylation extracted from peripheral blood cells, researchers have been previously criticized for neglecting the actual brain tissue. In response to this, DNA methylation has been investigated in postmortem brain tissues. However, various issues are encountered when studying postmortem brains including, the difficulty in obtaining a discordant twin sample, various epigenetic states being found in each part of the brain, brain tissue damage, and epigenetic changes due to lack of oxygen at the time of death.

For the purpose of solving such issues, studies using induced pluripotent stem (iPS) cells have been conducted. Neuronal iPS cells are established from skin cells or peripheral blood-derived cells and then induced to form neurons or glial cells. In one SCZ twin study, Nakazawa et al. (2017) discovered a MZ who had a mismatched clozapine response and was then able to establish iPS cell lines for both twins. Upon comparing the transcriptome profiles following treatment with clozapine, results showed the expression patterns differed between the iPS cell-derived differentiated neurons of the twins.

Recently, human pluripotent stem cells such as iPS cells have been used in three-dimensional (3D) culture techniques to create "organoids" that can reproduce the characteristics of certain small areas of human organs. Organoids can also be used to observe cell interactions in organs and within an extracellular environment. Although not a twin study, Mariani et al. (2015) developed iPS cells derived from patients with idiopathic ASD. Telencephalic organoids derived from iPS cells showed overexpression of the transcription factor FOXG1 and the overproduction of GABAergic neurons. Thus, by examining gene expressions of organoids, this can assist in the examination of causes of psychiatric disorders.

For mental disorders such as SCZ and ASD, it is believed that there is a genetic overlap between psychiatric disorders and disorders of the immune system (Michel et al. 2012). Genes related to the immune system exert various effects on synaptic pruning and plasticity, as well as the activity of microglia. Previous studies have shown excessively pruned synapses in SCZ and inappropriately pruned ones in ASD, which are believed to occasionally lead to excessive synapse formation (Liu et al. 2017). In synaptic pruning, microglia have been reported to play an important role (Frick et al. 2013) and a twin study revealed that microglia activation was related to the etiology of SCZ (Johansson et al. 2017).

It has also been shown that the other glial cell, the oligodendrocyte, can additionally contribute to the etiology of SCZ and ASD. For example, studies that examined the disrupted brain connectivity hypothesis in SCZ have provided evidence on impaired white matter tract integrity, decreased 
numbers of oligodendrocytes in the prefrontal cortex and hippocampus, along with reduced oligodendrocyte-related gene expression. Moreover, an oligodendrocyte deficit can cause impaired myelination with a subsequent lack of nerve impulse transmission and cognitive impairment related to SCZ. It has also been hypothesized that inflammation in the brain along with microglia overactivity is involved in oligodendrocyte dysfunction (Raabe et al. 2018, 2019).

Other studies have additionally tested this hypothesis using neuronal iPS cells. Windrem et al. (2017) transplanted glial progenitor cells generated from iPS cells into mouse brains to generate humanized glial chimeric mice. These mice exhibited both reduced white matter and myelination as compared to controls, along with reduced prepulse suppression, and abnormal behaviors such as excessive anxiety, antisocial characteristics, and sleep disturbances. This study has provided support for the presence of impaired glial maturation during the development of SCZ.

Although the 2D culture models of iPS cells are suitable for generating relatively homogeneous cell populations, this can be disadvantageous when examining the function of the neural network that connects the multiple cell types across different brain regions. Although the use of organoids in a 3D culture model can be advantageous for examining the relationships and gene expression of multiple cells, there are some limitations in studies using organoid that include: (1) cells from tissues other than the brain may sometimes be contaminated, (2) due to different embryonal origins, microglia cannot be included in almost all of the iPSC cellderived brain models and (3) conditions arising from longlasting processes such as aging and maturation are difficult to reproduce when using brain organoids (Quadrato et al. 2016; Raabe et al. 2018, 2019).

Future development of brain organoids will additionally allow for more detailed examinations of oligodendrocyte and microglia functions in the brain (Di Lullo and Kriegstein 2017; Koo et al. 2019). Therefore, etiological studies using brain organoids derived from MZs with different presentations of mental disorders are anticipated in the future.

Hopefully, these new types of research approaches may help to uncover useful insights into psychiatric disorders, including ASD and SCZ.

\section{Conclusion}

As previously discussed, there have been a large number of twin studies that have examined SCZ and ASD for an extended period of time. Epidemiological twin studies on psychiatric disorders that have been used to estimate heritability have shown that there is a large genetic influence on the onset of SCZ and ASD. Although biological twin studies for psychiatric disorders have attempted to detect genetic or epigenetic differences between MZs, a consensus for these findings has yet to be definitively perfected.

We consider the advantages of twin studies to be as follows: (1) when genome-wide association studies of psychiatric disorders are performed using extra-large sample sizes, the genetic heterogeneity makes it difficult to achieve clear results that are close to the etiology of the disorder. However, if a twin study is conducted to determine genetic or epigenetic differences between the twins, then it becomes possible to obtain definitive twin-specific findings. (2) Twin studies can be undertaken with a lower cost and manpower requirement as compared to extra-large sample sizes required when performing non-twin studies. (3) Because of the uniqueness of the participants, the subjects of twin studies may be comparatively easy to follow. Therefore, twin studies can sometimes be developed into longitudinal studies.

Based on these perceived advantages, which direction should twin studies be developed? While it is first important to increase the number of samples for twin studies, this does create some limitations. Second, the definition of "discordance" needs to be discussed. For example, the discordance of severity, age of onset, the profile of symptoms, course or prognosis, response to a specific drug might potentially need to be considered. Third, new technology that makes it possible to detect differences in the MZs with regard to genetic or epigenetic states, which includes somatic mutation, DNA methylation, histone chemical modification, noncoding RNA, or neural circuits remodeling, which includes synapse formation, synaptic pruning, microglial regulation, oligodendrocyte function and myelination, will need to be developed.

For a long period of time, MZs and DZs have played an important role when attempting to study the influences of genetic and environmental factors. Recently, new concepts have been developed, which include environmental factors that are internally based such as intestinal flora, and environment-related but transgenerational factors, which include maternally inherited histone protein modification "H3K27me3". However, researching discordant MZs remains a solid way for clarifying the etiology of psychiatric disorders. Research into MZs is expected to become more sophisticated as technological advancements make it possible to better detect the biological differences between MZs discordant for SCZ or ASD.

Funding None.

\section{Compliance with ethical standards}

Conflict of interest The authors declare that they have no conflict of interest. 
Open Access This article is licensed under a Creative Commons Attribution 4.0 International License, which permits use, sharing, adaptation, distribution and reproduction in any medium or format, as long as you give appropriate credit to the original author(s) and the source, provide a link to the Creative Commons licence, and indicate if changes were made. The images or other third party material in this article are included in the article's Creative Commons licence, unless indicated otherwise in a credit line to the material. If material is not included in the article's Creative Commons licence and your intended use is not permitted by statutory regulation or exceeds the permitted use, you will need to obtain permission directly from the copyright holder. To view a copy of this licence, visit http://creativecommons.org/licenses/by/4.0/.

\section{References}

Åberg K, Saetre P, Jareborg N, Jazin E (2006) Human QKI, a potential regulator of mRNA expression of human oligodendrocyterelated genes involved in schizophrenia. Proc Natl Acad Sci USA 103(19):7482-7487. https://doi.org/10.1073/pnas.0601213103

American Psychiatric Association (2013) Diagnostic and statistical manual of mental disorders, Fifth edition (DSM-5). American Psychiatric Association, Philadelphia

Asperger H (1938) Das psychisch abnorme Kind. Wien Klin Wochenschr 51:1314-1317

Asperger H (1944) Die 'Autistischen Psychopathen' im Kindesalter. Archiv fur Psychiatrie und Nervenkrankheiten 117:76-136

Besteher B, Brambilla P, Nenadić I (2020) Twin studies of brain structure and cognition in schizophrenia. Neurosci Biobehav Rev 109:103-113. https://doi.org/10.1016/j.neubiorev.2019.12.021

Bloom RJ, Kähler AK, Collins AL, Chen G, Cannon TD, Hultman C et al (2013) Comprehensive analysis of copy number variation in monozygotic twins discordant for bipolar disorder or schizophrenia. Schizophr Res 146(1-3):289-290

Bönsch D, Wunschel M, Lenz B, Janssen G, Weisbrod M, Sauer H (2012) Methylation matters? Decreased methylation status of genomic DNA in the blood of schizophrenic twins. Psychiatry Res 198(3):533-537

Brando LJ, Yolken R, Herman MM, Kleinman JE, Ross CA, Torrey EF (1996) Analysis of the DRPLA triplet repeat in brain tissue and leukocytes from schizophrenics. Psychiatr Genet 6(1):1-5

Camchong J, Lim KO, Sponheim SR, Macdonald AW (2009) Frontal white matter integrity as an endophenotype for schizophrenia: diffusion tensor imaging in monozygotic twins and patients' nonpsychotic relatives. Front Hum Neurosci. https:// doi.org/10.3389/neuro.09.035.2009. (eCollection. Published online 2009 Oct 26)

Cannon TD, Hennah W, van Erp TG, Thompson PM, Lonnqvist J, Huttunen $M$ et al (2005) Association of DISC1/TRAX haplotypes with schizophrenia, reduced prefrontal gray matter, and impaired short- and long-term memory. Arch Gen Psychiatry 62(11):1205-1213

Castellani CA, Awamleh Z, Melka MG, O’Reilly RL, Singh SM (2014) Copy number variation distribution in six monozygotic twin pairs discordant for schizophrenia. Twin Res Hum Genet 17(2):108-120

Castellani CA, Laufer B, Melka MG, Diehl EJ, O'Reilly RL, Singh SM (2015a) DNA methylation differences in monozygotic twin pairs discordant for schizophrenia identifies psychosis related genes and networks. BMC Med Genom 8:17

Castellani CA, Melka MG, Gui JL, O'Reilly RL, Singh SM (2015b) Integration of DNA sequence and DNA methylation changes in monozygotic twin pairs discordant for schizophrenia. Schizophr Res 169(1-3):433-440

Castellani CA, Melka MG, Gui JL, Gallo AJ, O’Reilly RL, Singh SM (2017) Post-zygotic genomic changes in glutamate and dopamine pathway genes may explain discordance of monozygotic twins for schizophrenia. Clin Transl Med 6(1):43

Cross-Disorder Group of the Psychiatric Genomics Consortium (2013) Identification of risk loci with shared effects on five major psychiatric disorders: a genome-wide analysis. Lancet 381(9875): 1371-1379

Deb-Rinker P, Klempan TA, O’Reilly RL, Torrey EF, Singh SM (1999) Molecular characterization of a MSRV-like sequence identified by RDA from monozygotic twin pairs discordant for schizophrenia. Genomics 61(2):133-144

Dempster EL, Pidsley R, Schalkwyk LC, Owens S, Georgiades A, Kane F et al (2011) Disease-associated epigenetic changes in monozygotic twins discordant for schizophrenia and bipolar disorder. Hum Mol Genet 20(24):4786-4796

Di Lullo E, Kriegstein AR (2017) The use of brain organoids to investigate neural development and disease. Nat Rev Neurosci 18(10):573-584. https://doi.org/10.1038/nrn.2017.107. (Epub 2017 Sep 7)

Ding HT, Taur Y, Walkup JT (2017) Gut microbiota and autism: key concepts and findings. J Autism Dev Disord 47(2):480-489. https://doi.org/10.1007/s10803-016-2960-9

Djaafri F, Stirnemann J, Mediouni I, Colmant C, Ville Y (2017) Twin-twin transfusion syndrome-what we have learned from clinical trials. Semin Fetal Neonatal Med 22(6):367-375

Farmer AE, McGuffin P, Gottesman II (1987) Twin concordance for DSM-III schizophrenia. Scrutinizing the validity of the definition. Arch Gen Psychiatry 44(7):634-641

Fisher HL, Murphy TM, Arseneault L, Caspi A, Moffitt TE, Viana $\mathrm{J}$ et al (2015) Methylomic analysis of monozygotic twins discordant for childhood psychotic symptoms. Epigenetics 10(11):1014-1023

Folstein S, Rutter M (1997) Genetic influences and infantile autism. Nature 265(5596):726-728

Frick LR, Williams K, Pittenger C (2013) Microglial dysregulation in psychiatric disease. Clin Dev Immunol. https://doi. org/10.1155/2013/608654

Froehlich-Santino W, Londono Tobon A, Cleveland S, Torres A, Phillips J, Cohen B, Torigoe T et al (2014) Prenatal and perinatal risk factors in a twin study of autism spectrum disorders. J Psychiatr Res 54:100-108. https://doi.org/10.1016/j.jpsychires .2014.03.019. Epub 2014 Mar 29

Fromm-Reichman F (1948) Notes on the development of treatment of schizophrenics by psychoanalytic psychotherapy. Psychiatry 11(3):263-273

Gandal MJ, Haney JR, Parikshak NN et al (2018) Shared molecular neuropathology across major psychiatric disorders parallels polygenic overlap. Science 359(6376):693-697

Hallmayer J, Cleveland S, Torres A, Phillips J, Cohen B, Torigoe $\mathrm{T}$ et al (2011) Genetic heritability and shared environmental factors among twin pairs with autism. Arch Gen Psychiatry 68(11):1095-1102

Haroutunian V, Katsel P, Dracheva S, Stewart DG, Davis KL (2007) Variations in oligodendrocyte-related gene expression across multiple cortical regions: implications for the pathophysiology of schizophrenia. Int J Neuropsychopharmacol 10:565-573

Hata A, Suzuki Y, Matsui I, Kuroki Y (1982) Ring 18 mosaicism in identical twins. Hum Genet 62(4):364-367

Henriksen MG, Nordgaard J, Jansson LB (2017) Genetics of schizophrenia: overview of methods, findings and limitations. Front Hum Neurosci 11:322

Hilker R, Helenius D, Fagerlund B, Skytthe A, Christensen K, Werge TM et al (2018) Heritability of schizophrenia and 
schizophrenia spectrum based on the Nationwide Danish Twin Register. Biol Psychiatry 83(6):492-498

Hrubec Z, Neel JV (1981) Familial factors in early deaths: twins followed 30 years to ages 51-61 in 1978. Hum Genet 59(1):39-46

Hu VW, Frank BC, Heine S, Lee NH, Quackenbush J (2006) Gene expression profiling of lymphoblastoid cell lines from monozygotic twins discordant in severity of autism reveals differential regulation of neurologically relevant genes. BMC Genom $7: 118$

Huang Y, Zhao Y, Ren Y, Yi Y, Li X, Gao Z, Zhan X, Yu J, Wang D, Liang S, Wu L (2019) Identifying genomic variations in monozygotic twins discordant for autism spectrum disorder using wholegenome sequencing. Mol Ther Nucleic Acids 14:204-211

Hulshoff Pol HE, van Baal GC, Schnack HG, Brans RG, van der Schot AC, Brouwer RM et al (2012) Overlapping and segregating structural brain abnormalities in twins with schizophrenia or bipolar disorder. Arch Gen Psychiatry 69:349-359. https://doi. org/10.1001/archgenpsychiatry.2011.1615

Johansson V, Jakobsson J, Fortgang RG, Zetterberg H, Blennow K, Cannon TD, Hultman CM, Wetterberg L, Landén M (2017) Cerebrospinal fluid microglia and neurodegenerative markers in twins concordant and discordant for psychotic disorders. Eur Arch Psychiatry Clin Neurosci 267(5):391-402. https://doi.org/10.1007/ s00406-016-0759-5

Johansson V, Hultman CM, Kizling I, Martinsson L, Borg J, Hedman A, Cannon TD (2019) The schizophrenia and bipolar twin study in Sweden (STAR). Schizophr Res 204:183-192. https://doi. org/10.1016/j.schres.2018.08.001

Kakiuchi C, Iwamoto K, Ishiwata M, Bundo M, Kasahara T, Kusumi I et al (2003) Impaired feedback regulation of XBP1 as a genetic risk factor for bipolar disorder. Nat Genet 35(2):171-175

Kakiuchi C, Ishiwata M, Nanko S, Ozaki N, Iwata N, Umekage T et al (2008) Up-regulation of ADM and SEPX1 in the lymphoblastoid cells of patients in monozygotic twins discordant for schizophrenia. Am J Med Genet B Neuropsychiatr Genet 147B(5):557-564

Kanner L (1943) Autistic disturbances of affective contact. Nervous Child 2:217-250

Kendler KS, Engstrom EJ (2018) Criticisms of Kraepelin's psychiatric nosology: 1896-1927. Am J Psychiatry 175(4):316-326

Kerns D, Vong GS, Barley K, Dracheva S, Katsel P, Casaccia P et al (2010) Gene expression abnormalities and oligodendrocyte deficits in the internal capsule in schizophrenia. Schizophr Res 120:150-158. https://doi.org/10.1016/j.schres.2010.04.012. (Epub 2010 May 23)

Kinoshita M, Numata S, Tajima A, Shimodera S, Ono S, Imamura A et al (2013) DNA methylation signatures of peripheral leukocytes in schizophrenia. Neuromol Med 15(1):95-101

Koo B, Choi B, Park H, Yoon KJ (2019) Past, present, and future of brain organoid technology. Mol Cells 42(9):617-627. https://doi. org/10.14348/molcells.2019.0162

Kruyer H, Milà M, Glover G, Carbonell P, Ballesta F, Estivill X (1994) Fragile $\times$ syndrome and the $(\mathrm{CGG}) n$ mutation: two families with discordant MZ twins. Am J Hum Genet 54(3):437-442

Laplana M, Royo JL, Aluja A, López R, Heine-Sunyer D, Fibla J (2014) Absence of substantial copy number differences in a pair of monozygotic twins discordant for features of autism spectrum disorder. Case Rep Genet. https://doi.org/10.1155/2014/516529

Le Couteur A, Bailey A, Goode S, Pickles A, Robertson S, Gottesman I et al (1996) A broader phenotype of autism: the clinical spectrum in twins. J Child Psychol Psychiatry 37(7):785-801

Li H, Bi R, Fan Y, Wu Y, Tang Y, Li Z et al (2017) mtDNA heteroplasmy in monozygotic twins discordant for schizophrenia. Mol Neurobiol 54(6):4343-4352

Liang S, Li Z, Wang Y, Li X, Yang X, Zhan X et al (2019) Genomewide DNA methylation analysis reveals epigenetic pattern of
SH2B1 in Chinese monozygotic twins discordant for autism spectrum disorder. Front Neurosci 13:712

Liu X, Li Z, Fan C, Zhang D, Chen J (2017) Genetics implicate common mechanisms in autism and schizophrenia: synaptic activity and immunity. J Med Genet 54(8):511-520. https://doi. org/10.1136/jmedgenet-2016-104487

Lyu N, Guan LL, Ma H, Wang XJ, Wu BM, Shang FH et al (2016) Failure to identify somatic mutations in monozygotic twins discordant for schizophrenia by whole exome sequencing. Chin Med J (Engl) 129(6):690-695

Maatz A, Hoff P (2014) The birth of schizophrenia or a very modern Bleuler: a close reading of Eugen Bleuler's 'Die Prognose der Dementia praecox' and a re-consideration of his contribution to psychiatry. Hist Psychiatry 25(4):431-440

Maiti S, Kumar KH, Castellani CA, O’Reilly R, Singh SM (2011) Ontogenetic de novo copy number variations (CNVs) as a source of genetic individuality: studies on two families with MZD twins for schizophrenia. PLoS One 6(3):e17125

Mandy W, Lai MC (2016) Annual research review: the role of the environment in the developmental psychopathology of autism spectrum condition. J Child Psychol Psychiatry 57(3):271-292

Mangiola F, Ianiro G, Franceschi F, Fagiuoli S, Gasbarrini G, Gasbarrini A (2016) Gut microbiota in autism and mood disorders. World J Gastroenterol 22(1):361-368. https://doi.org/10.3748/ wjg.v22.i1.361

Mariani J, Coppola G, Zhang P, Abyzov A, Provini L, Tomasini L et al (2015) FOXG1-dependent dysregulation of GABA/glutamate neuron differentiation in autism spectrum disorders. Cell 162:375-390. https://doi.org/10.1016/j.cell.2015.06.034

McDonald P, Lewis M, Murphy B, O'Reilly R, Singh SM (2003) Appraisal of genetic and epigenetic congruity of a monozygotic twin pair discordant for schizophrenia. J Med Genet 40(2):E16

Michel M, Schmidt MJ, Mirnics K (2012) Immune system gene dysregulation in autism and schizophrenia. Dev Neurobiol 72(10):1277-1287. https://doi.org/10.1002/dneu.22044

Miyake K, Yang C, Minakuchi Y, Ohori K, Soutome M, Hirasawa T, Kazuki Y, Adachi N, Suzuki S, Itoh M, Goto Y, Andoh T, Kurosawa H, Oshimura M, Sasaki M, Toyoda A, Kubota T (2013) Comparison of genomic and epigenomic expression in monozygotic twins discordant for Rett syndrome. PLoS One 8(6):e66729. https://doi.org/10.1371/journal.pone.0066729

Morimoto Y, Ono S, Imamura A, Okazaki Y, Kinoshita A, Mishima H et al (2017) Deep sequencing reveals variations in somatic cell mosaic mutations between monozygotic twins with discordant psychiatric disease. Hum Genome Var 4:17032

Murphy BC, O'Reilly RL, Singh SM (2005) Site-specific cytosine methylation in S-COMT promoter in 31 brain regions with implications for studies involving schizophrenia. Am J Med Genet B Neuropsychiatr Genet 133B(1):37-42

Murphy BC, O'Reilly RL, Singh SM (2008) DNA methylation and mRNA expression of SYN III, a candidate gene for schizophrenia. BMC Med Genet 9:115

Nagy C, Turecki G (2015) Transgenerational epigenetic inheritance: an open discussion. Epigenomics 7(5):781-790

Nakazawa T, Kikuchi M, Ishikawa M, Yamamori H, Nagayasu K, Matsumoto T et al (2017) Differential gene expression profiles in neurons generated from lymphoblastoid B-cell line-derived iPS cells from monozygotic twin cases with treatment-resistant schizophrenia and discordant responses to clozapine. Schizophr Res 181:75-82

Nguyen GH, Bouchard J, Boselli MG, Tolstoi LG, Keith L, Baldwin C, Nguyen NC, Schultz M, Herrera VL, Smith CL (2003) DNA stability and schizophrenia in twins. Am J Med Genet B Neuropsychiatr Genet 120B(1):1-10

Nguyen A, Rauch TA, Pfeifer GP, Hu VW (2010) Global methylation profiling of lymphoblastoid cell lines reveals epigenetic 
contributions to autism spectrum disorders and a novel autism candidate gene, RORA, whose protein product is reduced in autistic brain. FASEB J 24(8):3036-3051. https://doi. org/10.1096/fj.10-154484

Nishioka M, Bundo M, Ueda J, Yoshikawa A, Nishimura F, Sasaki T et al (2018) Identification of somatic mutations in monozygotic twins discordant for psychiatric disorders. NPJ Schizophr 4(1):7

O'Donnell KJ, Meaney MJ (2017) Fetal origins of mental health: the developmental origins of health and disease hypothesis. Am $\mathbf{J}$ Psychiatry 174(4):319-328

Okazaki Y (1995) A comprehensive twin study on genetic and nongenetic traits related to the etiologies of schizophrenia. Final report of Grant-in-Aid for Scientific Research (A) granted by the Ministry of Education, Culture, Sports, Science and Technology (MEXT) and the Japan Society for the Promotion of Science (JSPS)

Ono S, Imamura A, Tasaki S, Kurotaki N, Ozawa H, Yoshiura K et al (2010) Failure to confirm CNVs as of aetiological significance in twin pairs discordant for schizophrenia. Twin Res Hum Genet 13(5):455-460

Onstad S, Skre I, Torgersen S, Kringlen E (1991) Twin concordance for DSM-III-R schizophrenia. Acta Psychiatr Scand 83(5):395-401

Palma-Gudiel H, Eixarch E, Crispi F, Morán S, Zannas AS, Fañanás L (2019) Prenatal adverse environment is associated with epigenetic age deceleration at birth and hypomethylation at the hypoxia-responsive EP300 gene. Clin Epigenet 11:73. https:// doi.org/10.1186/s13148-019-0674-5

Picchioni MM, Rijsdijk F, Toulopoulou T, Chaddock C, Cole JH, Ettinger U et al (2017) Familial and environmental influences on brain volumes in twins with schizophrenia. J Psychiatry Neurosci 42:122-130

Pingault JB, Viding E, Galéra C, Greven CU, Zheng Y, Plomin R, Rijsdijk F (2015) Genetic and environmental influences on the developmental course of attention-deficit/hyperactivity disorder symptoms from childhood to adolescence. JAMA Psychiatry 72(7):651-658. https://doi.org/10.1001/jamapsychi atry.2015.0469

Polderman TJ, Hoekstra RA, Posthuma D et al (2014) The co-occurrence of autistic and ADHD dimensions in adults: an etiological study in 17,770 twins. Transl Psychiatry 4:e435

Polymeropoulos MH, Xiao H, Torrey EF, DeLisi LE, Crow T, Merril CR (1993) Search for a genetic event in monozygotic twins discordant for schizophrenia. Psychiatry Res 48(1):27-36

Quadrato G, Brown J, Arlotta P (2016) The promises and challenges of human brain organoids as models of neuropsychiatric disease. Nat Med 22:1220-1228. https://doi.org/10.1038/nm.4214. (Epub 2016 Oct 26)

Raabe FJ, Galinski S, Papiol S, Falkai PG, Schmitt A, Rossner MJ (2018) Studying and modulating schizophrenia-associated dysfunctions of oligodendrocytes with patient-specific cell systems. NPJ Schizophr 4:23. https://doi.org/10.1038/s41537-018-0066-4

Raabe FJ, Slapakova L, Rossner MJ, Cantuti-Castelvetri L, Simons M, Falkai PG et al (2019) Oligodendrocytes as a new therapeutic target in schizophrenia: from histopathological findings to neuron-oligodendrocyte interaction. Cells 8(12):E1496. https://doi. org/10.3390/cells8121496

Rio M, Royer G, Gobin S, de Blois MC, Ozilou C, Bernheim A, Nizon M, Munnich A, Bonnefont JP, Romana S, Vekemans M, Turleau C, Malan V (2013) Monozygotic twins discordant for submicroscopic chromosomal anomalies in 2 p25.3 region detected by array CGH. Clin Genet 84(1):31-36. https://doi.org/10.1111/ cge. 12036

Rutter M (2006) Genes and behavior: nature/nurture interplay explained. Blackwell publishing Ltd, London, p 41

Rutter M, Bartak L (1971) Causes of infantile autism: some considerations from recent research. J Autism Child Schizophr 1(1):20-32
Sandin S, Lichtenstein P, Kuja-Halkola R, Hultman C, Larsson H, Reichenberg A (2017) The heritability of autism spectrum disorder. JAMA 318(12):1182-1184

Sarachana T, Zhou R, Chen G, Manji HK, Hu VW (2010) Investigation of post-transcriptional gene regulatory networks associated with autism spectrum disorders by microRNA expression profiling of lymphoblastoid cell lines. Genome Med 2(4):23. https://doi. org/10.1186/gm144

Schmidt-Kastner R, van Os J, Esquivel G, Steinbusch HW, Rutten BP (2012) An environmental analysis of genes associated with schizophrenia: hypoxia and vascular factors as interacting elements in the neurodevelopmental model. Mol Psychiatry 17:1194-1205. https://doi.org/10.1038/mp.2011.183. (Epub 2012 Jan 31)

Schumacher A, Petronis A (2006) Epigenetics of complex diseases: from general theory to laboratory experiments. Curr Top Microbiol Immunol 310:81-115

Tabatabaiefar MA, Sajjadi RS, Narrei S (2019) Epigenetics and common non communicable disease. Adv Exp Med Biol 1121:7-20

Tang J, Fan Y, Li H, Xiang Q, Zhang DF, Li Z (2017) Whole-genome sequencing of monozygotic twins discordant for schizophrenia indicates multiple genetic risk factors for schizophrenia. J Genet Genom 44(6):295-306

Taylor MJ, Robinson EB, Happé F, Bolton P, Freeman D, Ronald A (2015) A longitudinal twin study of the association between childhood autistic traits and psychotic experiences in adolescence. Mol Autism 22(6):44. https://doi.org/10.1186/s1322 9-015-0037-9. (eCollection 2015)

Torrey EF (1992) Are we overestimating the genetic contribution to schizophrenia? Schizophr Bull 18(2):159-170

Torrey EF, Bowler AE, Taylor EH (1994a) Schizophrenia and manicdepressive disorder: the biological roots of mental illness as revealed by the landmark study of identical twins. Basic Books, New York, pp 1-3

Torrey EF, Bowler AE, Taylor EH (1994b) Schizophrenia and manicdepressive disorder: the biological roots of mental illness as revealed by the landmark study of identical twins. Basic Books, New York, pp 10-12

Torrey EF, Taylor EH, Bracha HS, Bowler AE, McNeil TF, Rawlings RR et al (1994c) Prenatal origin of schizophrenia in a subgroup of discordant monozygotic twins. Schizophr Bull 20:423-432. https://doi.org/10.1093/schbul/20.3.423

Tsujita T, Niikawa N, Yamashita H, Imamura A, Hamada A, Nakane $Y$ et al (1998) Genomic discordance between monozygotic twins discordant for schizophrenia. Am J Psychiatry 155(3):422-424

van Tilborg E, Achterberg EJM, van Kammen CM, van der Toorn A, Groenendaal F, Dijkhuizen RM et al (2018) Combined fetal inflammation and postnatal hypoxia causes myelin deficits and autism-like behavior in a rat model of diffuse white matter injury. Glia 66:78-93. https://doi.org/10.1002/glia.23216. (Epub 2017 Sep 19)

Vincent JB, Kalsi G, Klempan T, Tatuch Y, Sherrington RP, Breschel $T$ et al (1998) No evidence of expansion of CAG or GAA repeats in schizophrenia families and monozygotic twins. Hum Genet 103(1):41-47

Wahlström J, Steffenburg S, Hellgren L, Gillberg C (1989) Chromosome findings in twins with early-onset autistic disorder. Am J Med Genet 32(1):19-21

Weksberg R, Shuman C, Caluseriu O, Smith AC, Fei YL, Nishikawa $\mathrm{J}$ et al (2002) Discordant KCNQ1OT1 imprinting in sets of monozygotic twins discordant for Beckwith-Wiedemann syndrome. Hum Mol Genet 11(11):1317-1325

Windrem MS, Osipovitch M, Liu Z, Bates J, Chandler-Militello D, Zou L, Munir J et al (2017) Human iPSC glial mouse chimeras reveal glial contributions to schizophrenia. Cell Stem Cell 21:195-208. e6. https://doi.org/10.1016/j.stem.2017.06.012. (Epub 2017 Jul 20) 
Wing L (1996) Autistic spectrum disorders. BMJ 312(7027):327-328

Wong CC, Meaburn EL, Ronald A, Price TS, Jeffries AR, Schalkwyk LC, Plomin R, Mill J (2014) Methylomic analysis of monozygotic twins discordant for autism spectrum disorder and related behavioural traits. Mol Psychiatry 19(4):495-503. https://doi. org/10.1038/mp.2013.41. (Epub 2013 Apr 23)

Zenk F, Loeser E, Schiavo R, Kilpert F, Bogdanović O, Iovino N (2017) Germ line-inherited $\mathrm{H} 3 \mathrm{~K} 27 \mathrm{me} 3$ restricts enhancer function during maternal-to-zygotic transition. Science 357(6347):212-216
Zhao H, Nyholt DR (2017) Gene-based analyses reveal novel genetic overlap and allelic heterogeneity across five major psychiatric disorders. Hum Genet 136(2):263-274

Publisher's Note Springer Nature remains neutral with regard to jurisdictional claims in published maps and institutional affiliations. 